leucocytosis or a digestion leucopenia. Variation in a succession of bloodcounts developed in a large number of patients, whether the latter had been given milk or were fasting, and there was no definite evidence that the taking of food had any effect on the leucocytic curve. It is possible that the hourly and daily rhythm of the white corpuscles, described by Sabin and Shaw, may not be exactly the same in the mentally deranged as among normal individuals; but this must be a matter for future research, and has nothing to do with the subject of hæmoclasia.

C. S. R.

[185] Some aspects of the leucocyte associated with mental disorder.G. W. T. H. Fleming. Jour. of Ment. Sci., 1932, lxxviii, 129.

Botr the polynuclear count and the Schilling index show the presence, in acute and chronic cases of insanity, of an infected condition in a considerable proportion. Tuberculosis, although it is responsible for a certain small number of cases, is not the chief factor at work. Obscure sources of infection such as the gall-bladder, nasal sinuses and intestine, are probably the cause of the shifts to the left and low polynuclear counts which have been observed.

C. $\mathbf{S}$. .

\title{
PROGNOSIS AND TREATMENT.
}

[186] Sulfosin therapy in schizophrenia.-Lours Minski. Jour. of Ment. Sci., 1931, lxxvii, 792.

TwENTy patients suffering from schizophrenia were treated with sulfosin, of whom two recovered, one became much worse, and 15 showed no change. Heredity and sex appeared to have little bearing on the result of the treatment of patients in this series. The treatment appeared to be perfectly safe and without any serious risks. During the pyrexial period unpleasant symptoms in the form of pain, sickness, loss of appetite and headache prere common, but after the injections had been discontinued definite imporvement in the physical state occurred. Some degree of tolerance appeared to be produced, as shown by the diminished pyrexial reactions with successive doses of sulfosin. Blood-sugar levels on the whole appeared to be raised, with a tendency to delay in the return to normal of the blood-sugar.

C. $\mathbf{S .} \mathbf{R}$. 
[187] Experimental treatments of schizophrenia.-G. de M. Rudouph. Jour. of Ment. Sci., 1931, lxxvii, 767.

Twenty-Three treatments of schizophrenia are described and their relative values discussed, three series of untreated cases being used as controls. The treatments have been divided into groups, and a factor common to all producing improvements has been suggested. This factor is the ratio of the corpuscular bicarbonate to the corpuscular chloride, some treatments increasing the bicarbonate, some diminishing the chloride. The hope is expressed that this comparison of methods of treatment will stimulate those who possess the opportunity to adopt those methods which appear to be of value, so that the successful treatments may pass from the realm of hypothesis and experiment to that of theory and fact.

C. S. R.

[188] Treatment of general paralysis,-LeLand E. Hinsie and JosePH $\mathbf{R}$. Blalock. Amer. Jour. Psychiat., 1931, xi, 541.

ThIs paper comprises a report, from clinical and laboratory standpoints, of 197 patients with general paralysis treated from July, 1923, to July, 1926. It covers three separate methods of treatment, viz., (1) malaria, (2) tryparsamide, and (3) combined malaria and tryparsamide. There were 125 males and 72 females. Irrespective of the type of treatment, the remission rate was $22 \cdot 3$ per cent., the deaths amounted to $40 \cdot 2$ per cent. In 193018 per cent. of the original group were considerably improved and 20 per cent. were considered unimproved. Of all the patients living in 1930 57 per cent. were at home and 43 per cent. were in hospitals for the care of the mentally sick. The clinical outcome in the female group was more favourable than in the male. The highest remission rate was in those treated by tryparsamide (and mercury) alone, and the percentage of deaths in those treated by malaria alone and by tryparsamide alone was about the same. 'Those classified as 'expansive' experienced the highest remission rate, those with a schizophrenic colouring had the lowest. In 1930 the blood Wasermann reaction was negative in $77 \cdot 7$ per cent.; the spinal fluid Wassermann was negative in $83 \cdot 1$ per cent.; the colloidal gold curve was negative in 93.7 per cent. The greatest incidence of negativity occurred among those who received tryparsamide and in those who were classified as ' simple dementing.' 
[189] Treatment of stupor.-KARL H. Langenstrass. Amer. Jour. Psychiat., 1931, xi, 447.

Twelve stuporous catatonics were treated by the Lœvenhart method (respiratory stimulation by the inhalation of carbon dioxide and oxygen). Five patients showed only a transient period of responsiveness that lasted from 20 to 30 minutes. In these cases no lasting improvement of the clinical picture was observed. One patient remained stupor-free for a period of four hours immediately following the carbon dioxide inhalation. In two of the group the treatment was followed by a period of responsiveness extending over one week. Thereafter they withdrew gradually into the stupor state. Four had the stupor-free period for many months and these have so far not shown any tendency to relapse. Furthermore, in all four the inhalation was seen to initiate a marked and gratifying improvement of their entire mental and physical condition. On the view that possibly a combination of several methods might increase the effect of the Lœvenhart treatment, for three weeks previous to the gas treatment efforts were made to establish somewhat of a rapport, therapeutic suggestions were made and a series of 10 intravenous injections of a diluted streptococcus vaccine were made at two-day intervals.

C. S. R.

[190] Clinical findings in ' recovered' cases of schizophrenia.-Nolan D. C. Lewis and Elsie Blanchard. Amer. Jour. Psychiat., 1931, xi, 481 .

IN 41 per cent. of the cases there was a reliable family history of mental disorder sufficiently serious to be of some importance in evaluating hereditary factors. Only 26 per cent. had made a satisfactory economic prepsychotic adjustment and only 27 per cent. of the 88 men who had been in military service had given good and efficient service. Such mental symptoms as are usually considered to be of more malignant import, such as hypochondriasis, occurred in 52 per cent., odd bizarre mannerisms in 35 per cent., excessive autistic thinking in 43 per cent., paranoid elaborations in 47 per cent., and auditory hallucinations in as many as 69 per cent. More benign expressions such as active depression was seen in 27 per cent., grandiosity in 21 per cent. Confusion was present in 45 per cent. Ability to re-establish emotional cathexes and interests in the environment is undoubtedly impaired in practically all persons who have suffered from such severe schizophry reactions.

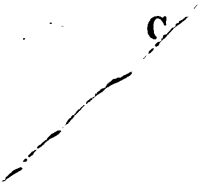

